\title{
LUNG Year in Review: 2020
}

\author{
Peter V. Dicpinigaitis ${ }^{1}$
}

Accepted: 2 January 2021 / Published online: 26 January 2021

(c) The Author(s), under exclusive licence to Springer Science+Business Media, LLC part of Springer Nature 2021

The journal $L U N G$ has been in continuous publication since 1903. Established as a German-language publication, $L U N G$ transformed to an exclusively English-language journal in the 1970s. The journal continues to enjoy an international readership as well as manuscript submissions from authors worldwide.

The year 2020 marked the retirement of Editor-in-Chief F. Dennis McCool, MD, under whose 17-year stewardship $L U N G$ continued to grow, flourish, and firmly establish itself as a leading journal in the space of pulmonary medicine. Manuscript submissions to the journal have steadily increased in quantity and quality, thus resulting in our current acceptance rate of submitted manuscripts of under $15 \%$. Although full-year data were not yet available at the time of this writing, journal article downloads in 2020 were on track to far exceed the 117,349 article downloads of 2019.

At the beginning of $2020 \mathrm{I}$ had the honor of assuming the role of Editor-in-Chief of $L U N G$. The journal and I owe Dr. $\mathrm{McCool}$ a great debt for his many years of outstanding service, and for facilitating a smooth transition for me and other new members of the editorial team. A positive aspect of any change in leadership is that it allows for evaluation, reflection, and establishment of new strategies for ongoing success. To that end, among my first actions as Editor-in-Chief was to bring on an outstanding group of Associate Editors who comprise a truly international body of expertise in the various fields within pulmonary and critical care medicine. We have no doubt that the intellectual energy, creativity, and enthusiasm of this new group of renowned clinicians and scientists will continue to move the journal forward in a positive trajectory.

In terms of specific goals, we aim to publish at least one State-of-the-Art review article in each edition of the journal. State-of-the-Art reviews are comprehensive reviews on

Peter V. Dicpinigaitis

pdicpin@gmail.com

1 Albert Einstein College of Medicine and Montefiore Medical Center, 1825 Eastchester Road, Bronx, NY 10461, USA a specific topic written by experts in the field. Such articles are typically invited, however, outstanding, unsolicited reviews will be considered as well. In 2020, we were pleased to publish 15 State-of-the-Art reviews [1-15] within our six issues. In keeping with our goal of enhancing the critical care content within the journal, publications in 2020 included a State-of-the-Art review of lung ultrasound in the assessment and management of acute respiratory failure [1], as well as articles reporting vaping-induced acute respiratory failure [16]; the use of diaphragmatic ultrasound to facilitate liberation from mechanical ventilation [17]; intensive care unit (ICU) utilization practices for patients with COPD [18]; biomarkers in sepsis-associated acute lung injury [19]; and optimal ventilator management during extracorporeal membrane oxygenation (ECMO) [20].

The year 2020 witnessed a pandemic of COVID-19-related manuscript submissions to medical journals, and $L U N G$ was not immune to the onslaught. As of December 31, 2020, a National Library of Medicine (PubMed) search of the term "COVID-19" yielded over 88,000 articles. We at $L U N G$ were very selective in our acceptance of SARSCoV-2-related manuscripts, since most submissions were retrospective, descriptive series of patients, often small in number and not contributing to the extant published literature. Four notable exceptions included the first study reporting an association of COVID-19 outcome with levels of surfactant protein D [21]; a study of the effect of COVID-19 on patients with sarcoidosis [22]; a State-of-the-Art review on the relevance of the ACE-2 receptor in SARS-CoV-2 infection [14]; and an editorial examining chronic cough as a residual effect of the illness [23].

We were delighted that in 2020, pediatric pulmonology was well represented within the pages of our journal. In addition to featuring a State-of-the Art review on the evaluation and management of children with obstructive sleep apnea syndrome (OSAS) [5], we published studies on cystic fibrosis (CF) [24-26] and non-CF-related pediatric topics [27-29]. We remain eager to publish high-quality articles in the field of pediatric respiratory medicine, and encourage 
authors working in this area to consider submission of their highest quality work to $L U N G$.

As would be expected, studies in obstructive airways disease comprised a large portion of our published articles. New aspects of pathophysiology and diagnosis of asthma were described in both clinical and basic investigations [30-37]. In keeping with historical precedent, COPD-related research played a prominent role in each issue of the journal $[18,38-50]$.

Pulmonary arterial hypertension (PAH) continues to be among the most active fields of inquiry in respiratory medicine. In addition to a State-of-the-Art review of treatment guidelines for PAH [7], we published a number of studies exploring clinical aspects of this condition [51-56].

Fueled by the recent availability of therapeutic options, investigative work in the areas of interstitial lung disease (ILD) and idiopathic pulmonary fibrosis (IPF) proceeds with enthusiasm. Reflecting the emergence of information in this field, $L U N G$ featured three relevant State-of-the-Art reviews $[6,8,10]$, as well as an eclectic selection of clinical studies [56-62].

The greatest amount of current research in pulmonary medicine is undoubtedly committed to the study of lung cancer. New discoveries and insights are emerging at a remarkable rate. Participating in the dissemination of this plethora of information, $L U N G$ published a State-of-the-Art review on new developments in the management of non-small cell lung cancer [15] as well as a collection of articles examining lung cancer epidemiology, screening, multidisciplinary management, surgical intervention, prognosis, and outcomes [63-74].

Emerging as one of the most prolific areas of investigation in pulmonary medicine is the field of sleep disorders. In 2020, we published two articles on pediatric obstructive sleep apnea syndrome (OSAS) [5, 27], including a State-ofthe-Art review on the evaluation and management of children with OSAS [5]. Studies in adult OSAS included therapy [79], adherence [76], risk of occupational injury [78], and possible associated biomarkers $[75,77,80]$.

$L U N G$ has historically given prominent attention to the important topic of cough. Cough is the most common complaint for which persons in the United States seek medical attention [81]. Thankfully, the last decade has seen a great increase in cough-related research which has led to multiple antitussive drug development programs currently underway [9]. Cough-related articles featured in 2020 included Stateof-the-Art reviews on the placebo effect in cough clinical trials [2], the role of excipients in antitussive preparations [11], and an update on the status of chronic cough in China [3]. Other topics covered were drug-associated cough [82], therapeutic strategies for chronic cough [79, 83], the role of cough assessment in monitoring patients with asthma [36] and COPD [47], the question of whether there will be an emergence of a post-COVID-19 chronic cough [23], and abstracts from the Seventh American Cough Conference [84].

The field of lung transplantation was addressed in a Stateof-the-Art review of infectious complications in this patient population [13], while other articles examined post-transplant bronchiolitis obliterans syndrome in CF patients [85] as well as cytomegalovirus reactivation in lung transplant recipients [86].

Interventional pulmonology and thoracic surgery received deserved attention, with multiple articles addressing the evolving field of bronchoscopic lung volume reduction surgery [87-89], as well as percutaneous interventions [59, 90], and surgical procedures $[12,74,91]$. Other contributions addressed aspects of respiratory physiology [29, 89, 92], pulmonary rehabilitation [93, 94], tuberculosis [95], nontuberculous mycobacterial infection [96], and World Trade Center-related lung disease [97].

Basic science provides the foundation from which clinical progress results. In 2020, we were pleased to publish several quality preclinical trials in the area of acute lung injury [98-101] as well as studies pertaining to asthma [32], lung cancer [66], cystic fibrosis [102, 103], pulmonary fibrosis [104], and mechanisms of pulmonary drug delivery [105].

The year 2020 was an exciting and productive one at $L U N G$. We look forward to ongoing progress at our journal. To achieve that goal, we will continue to rely on our colleagues worldwide, working at the bedside and in the laboratory, to contribute their quality work to $L U N G$.

\section{Compliance with Ethical Standards}

Conflict of interest Peter Dicpinigaitis, MD, is the Editor-in-Chief of $L U N G$. No other conflicts of interest related to the content of this editorial.

\section{References}

1. Islam M, Levitus M, Eisen L, Shiloh AL, Fein D (2020) Lung ultrasound for the diagnosis and management of acute respiratory failure. Lung 198(1):1-11

2. Eccles R (2020) The powerful placebo effect in cough: relevance to treatment and clinical trials. Lung 198(1):13-21

3. Lai K, Long L (2020) Current status and future directions of chronic cough in China. Lung 198(1):23-29

4. Haramati A, Haramati LB (2020) Imaging of chronic thromboembolic disease. Lung 198(2):245-255

5. Bitners AC, Arens R (2020) Evaluation and management of children with obstructive sleep apnea syndrome. Lung 198(2):257-270

6. Varone F, Iovene B, Sgalla G, Calvello M, Calabrese A, Larici AR, Richeldi L (2020) Fibrotic hypersensitivity pneumonitis: diagnosis and management. Lung 198(3):429-440 
7. Vazquez ZGS, Klinger JR (2020) Guidelines for the treatment of pulmonary arterial hypertension. Lung 198(4):581-596

8. Gibson CD, Kugler MC, Deshwal H, Munger JS, Condos R (2020) Advances in targeted therapy for progressive fibrosing interstitial lung disease. Lung 198(4):597-608

9. Dicpinigaitis PV, McGarvey LP, Canning BJ (2020) P2X3receptor antagonists as potential antitussives: summary of current clinical trials in chronic cough. Lung 198(4):609-616

10. Jeganathan N, Sathananthan M (2020) Connective tissue disease-related interstitial lung disease: prevalence, patterns, predictors, prognosis, and treatment. Lung 198(5):735-759

11. Eccles R (2020) What is the role of over 100 excipients in over the counter (OTC) cough medicines? Lung 198(5):727-734

12. Tanner TG, Colvin MO (2020) Pulmonary complications of cardiac surgery. Lung 198(6):889-896

13. Trachuk P, Bartash R, Abbasi M, Keene A (2020) Infectious complications in lung transplant recipients. Lung 198(6):879-887

14. Scialo F, Daniele A, Amato F et al (2020) ACE2: the major cell entry receptor for SARS-CoV-2. Lung 198(6):867-877

15. Alexander M, Kim SY, Cheng H (2020) Update 2020: management of non-small cell lung cancer. Lung 198(6):897-907

16. Dicpinigaitis PV, Trachuk P, Fakier F et al (2020) Vaping-associated acute respiratory failure due to acute lipoid pneumonia. Lung 198(1):31-33

17 McCool FD, Oyieng'o DO, Koo P (2020) The utility of diaphragm ultrasound in reducing time to extubation. Lung 198(3):499-505

18. Matthews KS, Goel NN, Vargas-Torres C et al (2020) A crosssectional study of hospital performance on ICU utilization practices for patients with chronic obstructive pulmonary disease. Lung 198(4):637-644

19. Li G, Zhang L, Han N et al (2020) Increased Th17 and Th22 cell percentages predict acute lung injury in patients with sepsis. Lung 198(4):687-693

20. Gupta E, Awsare B, Hiroshi H et al (2020) Don't drive blind: driving pressure to optimize ventilator management in ECMO. Lung 198(5):785-792

21. Kerget B, Kerget F, Kocak AO et al (2020) Are serum interleukin 6 and surfactant protein D levels associated with the clinical course of COVID-19? Lung 198(5):777-784

22. Morgenthau AS, Levin MA, Freeman R et al (2020) Moderate or severe impairment in pulmonary function is associated with mortality in sarcoidosis patients infected with SARS-CoV-2. Lung 198(5):771-775

23. Dicpinigaitis PV, Canning BJ (2020) Is there (will there be) a post-COVID-19 chronic cough? Lung 198(6):863-865

24. Procianoy EDFA, de Abreu e Silva FA, Marostica PJC et al (2020) Chloride conductance, nasal potential difference and cystic fibrosis pathophysiology. Lung 198(1):151-156

25. Kasi AS, Wee CP, Keens TG et al (2020) Abnormal lung clearance index in cystic fibrosis screen positive, inconclusive diagnosis (CFSPID) children with otherwise normal FEV1. Lung 198(1):163-167

26. Sagwal S, Chauhan A, Kaur J et al (2020) Association of serum TGF- $\beta 1$ levels with different clinical phenotypes of cystic fibrosis exacerbation. Lung 198(2):377-383

27. Shafiek H, Evangelisti M, Abd-elwahab NH et al (2020) Obstructive sleep apnea in school-aged children presented with nocturnal enuresis. Lung 198(1):187-194

28. Collaro AJ, Chang AB, Marchant JM et al (2020) Culturally appropriate outreach specialist respiratory medical care improves the lung function of children in regional and remote Queensland. Lung 198(2):361-369

29. Kotwal N, Shukla PJ, Perez GF (2020) Peak cough flow in children with neuromuscular disorders. Lung 198(2):371-375
30. Ramonell RP, Iftikhar IH (2020) Effect of anti-IL5, anti-IL5R, anti-IL13 therapy on asthma exacerbations: a network metaanalysis. Lung 198(1):95-103

31. Matloubi M, Ranjbar M, Assarehzadegan M-A et al (2020) The impact of interleukin (IL)-33 gene polymorphisms and environmental factors on risk of asthma in the Iranian population. Lung 198(1):105-112

32. Whitehead GS, Hussain S, Fannin R et al (2020) TLR5 activation exacerbates airway inflammation in asthma. Lung 198(2):289-298

33. Huang J, Liu J, Xian Y et al (2020) Elevated circulating CD4 ${ }^{+}$ $\mathrm{CD} 25^{+} \mathrm{CD} 127^{- \text {llow }}$ regulatory $\mathrm{T}$ cells in patients with non-asthmatic eosinophilic bronchitis. Lung 198(3):491-497

34. Voelker D, Almodallal Y, Scrodin MD et al (2020) Newer biological agents in the treatment of severe asthma: real-world results from a tertiary referral center. Lung 198(4):653-659

35. Ventaggiato L, Perruzza M, Refini RM et al (2020) Mepolizumab and benralizumab in severe eosinophilic asthma: preliminary results of a proteomic study. Lung 198(5):761-765

36. Faruqi S, Sykes DL, Crooks MG et al (2020) Objective assessment of cough: an early marker of response to biological therapies in asthma? Lung 198(5):767-770

37. Alzghoul BN, Reddy R, Chizinga M et al (2020) Pulmonary embolism in acute asthma exacerbation: clinical characteristics, prediction model and hospital outcomes. Lung 198(4):661-669

38. Hallowell RW, Schwartzstein R, O'Donnell CR et al (2020) Controlled delivery of $80 \mathrm{mg}$ aerosol furosemide does not achieve consistent dyspnea relief in patients. Lung 198(1):113-120

39. Meservey AJ, Burton MC, Priest J et al (2020) Risk of readmission and mortality following hospitalization with hypercapnic respiratory failure. Lung 198(1):121-134

40. Rodrigues A, Mara de Oliveira J, Furlanetto KC et al (2020) Are the effects of high-intensity exercise training different in patients with COPD versus COPD+asthma overlap? Lung 198(1):135-141

41. Tran D, Lim M, Vogrin S et al (2020) Point of care portable spirometry in the diagnosis and treatment of inpatients with chronic obstructive pulmonary disease. Lung 198(1):143-150

42. Harlander M, Lestan D, Turel M (2020) Chitotriosidase activity in plasma and COPD exacerbations. Lung 198(2):299-306

43. Kerget B, Afsin DE, Kerget $F$ et al (2020) Is Metrnl an adipokine involved in the anti-inflammatory response to acute exacerbations of COPD? Lung 198(2):307-314

44. Kardos P, Vogelmeier CF, Worth $\mathrm{H}$ et al (2020) COPD assessment test changes from baseline correlate with COPD exacerbations: a longitudinal analysis of the DACCORD observational study. Lung 198(3):507-514

45. Ghobadi H, Hosseini N, Aslani MR (2020) Correlations between serum decoy receptor 3 and airflow limitation and quality of life in male patients with stable stage and acute exacerbation of COPD. Lung 198(3):515-523

46. Upadhyay J, Trivedi N, Lal A (2020) Risk of future type 2 diabetes mellitus in patients developing steroid-induced hyperglycemia during hospitalization for chronic obstructive pulmonary disease exacerbation. Lung 198(3):525-533

47. Cho PSP, Fletcher HV, Turner RD et al (2020) The relationship between cough reflex sensitivity and exacerbation frequency in chronic obstructive pulmonary disease. Lung 198(4):617-628

48. De Weger WW, Klooster K, ten Hacken NH et al (2020) Determining static hyperinflation in patients with severe emphysema: relation between lung function parameters and patient-related outcomes. Lung 198(4):629-636

49. Huang S-J, Ding Z-N, Xiang H-X et al (2020) Association between serum S100A8/S100A9 heterodimer and pulmonary function in patients with acute exacerbation of chronic obstructive pulmonary disease. Lung 198(4):645-652 
50. Saito Z, Yoshida M, Kojima A et al (2020) Benefits and risks of inhaled corticosteroid treatment in patients with chronic obstructive pulmonary disease classified by blood eosinophil counts. Lung 198(6):925-931

51. Kimmig LM, Liao C, Bag R (2020) Ambulatory transition from parenteral prostanoid to inhaled treprostinil in patients with pulmonary arterial hypertension. Lung 198(1):53-58

52. Rashid F, Parvizi R, Bilejani E et al (2020) Evaluation of the incidence of chronic thromboembolic pulmonary hypertension 1 year after first episode of acute pulmonary embolism: a cohort study. Lung 198(1):59-64

53. Wronski SL, Mordin M, Kelley K et al (2020) The role of noninvasive endpoints in predicting long-term outcomes in pulmonary arterial hypertension. Lung 198(1):65-86

54. Tooba R, Almoushref A, Tonelli AR (2020) Is there value in repeating inhaled nitric oxide vasoreactivity tests in patients with pulmonary arterial hypertension? Lung 198(1):87-94

55. Schoenberg NC, Argula RG, Klings ES et al (2020) Prevalence and mortality of pulmonary hypertension in ESRD: a systematic review and meta-analysis. Lung 198(3):535-545

56. Sobiecka M, Lewandowska K, Kober J et al (2020) Can a new scoring system improve prediction of pulmonary hypertension in newly recognized interstitial lung diseases? Lung 198(3):547-554

57. Hosein KS, Sergiacomi G, Zompatori M et al (2020) The CALIPER-revised version of the composite physiologic index is a better predictor of survival in IPF than the original version. Lung 198(1):169-172

58. Moll SA, Wiertz IA, Vorselaars ADM et al (2020) Change in serum biomarker CA $15-3$ as an early predictor of response to treatment and survival in hypersensitivity pneumonitis. Lung 198(2):385-393

59. Adams TN, Batra K, Silhan L et al (2020) Utility of bronchoalveolar lavage and transbronchial biopsy in patients with interstitial lung disease. Lung 198(5):803-810

60. Gibson CD, Bhatt A, Deshwal H et al (2020) Comparison of clinical measures among interstitial lung disease (ILD) patients with usual interstitial pneumonia (UIP) patterns on high-resolution computed tomography. Lung 198(5):811-819

61. Zinellu A, Paliogiannis P, Sotgiu E et al (2020) Blood cell count derived inflammation indexes in patients with idiopathic pulmonary fibrosis. Lung 198(5):821-827

62. Ritzenthaler JD, Zhang M, Torres-Gonzalez E et al (2020) The integrin inhibitor cilengitide and bleomycin-induced pulmonary fibrosis. Lung 198(6):947-955

63. Galvez-Nino M, Ruiz R, Pinto JA et al (2020) Lung cancer in the young. Lung 198(1):195-200

64. Kasmann L, Abdo R, Eze C et al (2020) External validation of a survival score for limited-stage small cell lung cancer patients treated with chemoradiotherapy. Lung 198(1):201-206

65. Wang C, Jin S, Xu S et al (2020) High systemic immuneinflammation index (SII) represents an unfavorable prognostic factor for small cell lung cancer treated with etoposide and platinum-based chemotherapy. Lung 198(2):405-414

66. Hu B, Li X, Chen L et al (2020) High expression of CARM inhibits lung cancer progression by targeting $\mathrm{TP}_{53}$ by regulating CTNNB $_{1}$. Lung 198(2):415-422

67. Adachi Y, Matsumoto K, Enomoto T (2020) Lung cancer in young patients: the importance of assessing driver mutations and treatment strategies [letter]. Lung 198(2):425-426

68. Thein KZ, Quick DP, Htut TW et al (2020) Impact of primary ambulatory thromboprophylaxis (PATP) with low-molecular weight heparins (LMWHs) on survival in patients with lung cancer receiving chemotherapy. Lung 198(3):575-579

69. Yilmaz A, Tekin SB, Bilici $M$ et al (2020) The significance of controlling nutritional status (CONUT) score as a novel prognostic parameter in small cell lung cancer. Lung 198(4):695-704

70. Ponvilawan B, Charoenngam N, Rujirachun P et al (2020) Chronic hepatitis $\mathrm{C}$ virus infection is associated with an increased risk of lung cancer: a systematic review and metaanalysis. Lung 198(4):705-714

71. Zhou X, Wu C, Cheng Q (2020) Negative lymph node count predicts survival of resected non-small cell lung cancer. Lung 198(5):839-846

72. Gazourian L, Durgana CS, Huntley D et al (2020) Quantitative pectoralis muscle area is associated with the development of lung cancer in a large lung cancer screening cohort. Lung 198(5):847-853

73. Albano D, Bilfinger T, Feraca M et al (2020) A multidisciplinary lung cancer program: does it reduce delay between diagnosis and treatment? Lung 198(6):967-972

74. Gowing S, Baker L, Tran A et al (2020) Postoperative adverse events are associated with oncologic recurrence following curative-intent resection for lung cancer. Lung 198(6):973-981

75. Horvath P, Lazar Z, Galffy G et al (2020) Circulating P-selectin glycoprotein ligand 1 and P-selectin levels in obstructive sleep apnea patients. Lung 198(1):173-179

76. Saoud M, Saeed M, Patel S et al (2020) Positive airway pressure adherence in patients with obstructive sleep apnea with schizophrenia. Lung 198(1):181-185

77. Kerget B, Afsin DE, Kerget $F$ et al (2020) Is vimentin the cause or effect of obstructive sleep apnea development? Lung 198(2):275-282

78. Hirsch Allen AJ, Peres B, Ayas NT (2020) Obstructive sleep apnea severity and the risk of occupational injury: a prospective observational cohort. Lung 198(2):283-287

79. Sundar KM, Willis AM, Smith S et al (2020) A randomized, controlled, pilot study of CPAP for patients with chronic cough and obstructive sleep apnea. Lung 198(3):449-457

80. Peres BU, Hirsch Allen AJ, Kendzerska T et al (2020) Obstructive sleep apnea severity, body mass index, and circulating levels of cellular adhesion molecules. Lung 198(6):939-945

81. Rui P, Okeyode T (2019) National Ambulatory Medical Care Survey: 2016 national summary tables. https://www.cdc.gov/ nchs/ahcd/ahcd_products.htm

82. Dicpinigaitis PV, Satia I, Ferguson N (2020) Falsely accused? Insufficient evidence to conclude that sitagliptin is a cause of chronic cough. Lung 198(2):271-273

83. Descazeaux M, Brouquières D, Didier A et al (2020) Obesity predicts treatment response to proton pump inhibitor therapy in patients with chronic cough. Lung 198(3):441-448

84. Abstracts from the Seventh American Cough Conference (2020) Lung 198(1):35-41

85. Hayes D Jr, Harhay MO, Nicol KK et al (2020) Lung T-cell profile alterations are associated with bronchiolitis obliterans syndrome in cystic fibrosis lung transplant recipients. Lung 198(1):157-161

86. Kwak SH, Lee SH, Park MS et al (2020) Risk factors for Cytomegalovirus reactivation in lung transplant recipients. Lung 198(5):829-838

87. May N, Niehaus-Gebele C, Reichenberger F et al (2020) Screening for bronchoscopic lung volume reduction: reasons for not receiving interventional treatment. Lung 198(1):221-228

88. Fiorelli A, Cascone R, Natale G et al (2020) Cardio-pulmonary changes after bronchoscopic lung volume reduction with endobronchial one-way valves. Lung 198(3):565-573

89. Van Dijk M, Klooster K, Hartman JE et al (2020) Change in dynamic hyperinflation after bronchoscopic lung volume reduction in patients with emphysema. Lung 198(5):795-801 
90. Tan J, Chen H, He J et al (2020) Needle aspiration versus closed thoracostomy in the treatment of spontaneous pneumothorax: a meta-analysis. Lung 198(2):333-344

91. Husch HH, Watte G, Zanon M et al (2020) Effects of transcutaneous electrical nerve stimulation on pain, pulmonary function, and respiratory muscle strength after posterolateral thoracotomy: a randomized controlled trial. Lung 198(2):345-353

92. Ioachimescu OC, Stoller JK (2020) Area under the expiratory flow-volume curve (AEX): assessing bronchodilator responsiveness. Lung 198(3):471-480

93. Reyes A, Castillo A, Castillo J (2020) Effects of expiratory muscle training and air stacking on peak cough flow in individuals with Parkinson's disease. Lung 198(1):207-211

94. Hill K, Ng LWC, Cecins N et al (2020) Effect of using a wheeled walker on physical activity and sedentary time in people with chronic obstructive pulmonary disease: a randomised cross-over trial. Lung 198(1):213-219

95. de Matto PM, Rodrigues Pereira G, Silva Barbosa M et al (2020) Association of Xpert MTB/RIF cycle threshold values with tuberculosis treatment outcomes. Lung 198(6):985-999

96. Eisenberg I, Yasin A, Fuks L et al (2020) Radiologic characteristics of non-tuberculous mycobacteria infection in patients with bronchiectasis. Lung 198(4):715-722

97. Weber J, Reeves AP, Doucette JT et al (2020) Quantitative CT evidence of airway inflammation in WTC workers and volunteers with low FVC spirometric pattern. Lung 198(3):555-563

98. Bersten AD, Krupa M, Griggs K et al (2020) Reduced surfactant contributes to increased lung stiffness induced by rapid inspiratory flow. Lung 198(1):43-52
99. Abe K, Horiguchi T, Enzan K et al (2020) Nicorandil, a $\mathrm{K}_{\text {ATP }}$ channel opener, attenuates ischemia-reperfusion injury in isolated rat lungs. Lung 198(2):315-321

100. Lian N, Zhang S, Huang J et al (2020) Resveratrol attenuates intermittent hypoxia-induced lung injury by activating the Nrf2/ ARE pathway. Lung 198(2):323-331

101. Zou F, Su X, Pan P (2020) Toll-like receptor-4-mediated inflammation is involved in intermittent hypoxia-induced lung injury. Lung 198(5):855-862

102. Leuer L, Krill A, Wilkens $H$ et al (2020) The phagocytosis of blood leukocytes from cystic fibrosis patients is not impaired in general. Lung 198(1):235-239

103. Youssef M, De Sanctis JB, Shah J et al (2020) Age-dependent progression in lung pathophysiology can be prevented by restoring fatty acid and ceramide imbalance in cystic fibrosis. Lung 198(3):459-469

104. Ritzenhaler JD, Zhang M, Torres-Gonzalez E et al (2020) The integrin inhibitor cilengitide and bleomycin-induced pulmonary fibrosis. Lung 198(6):947-955

105. Baer B, McCaig L, Yamashita C et al (2020) Exogenous surfactant as a pulmonary delivery vehicle for budesonide in vivo. Lung 198(6):909-916

Publisher's Note Springer Nature remains neutral with regard to jurisdictional claims in published maps and institutional affiliations. 